\title{
ESTUDO DA CISTICERCOSE EM PACIENTES PORTADORES DE EPILEPSIA RESIDENTES EM MUNICÍPIOS DO CARIRI PARAIBANO
}

\author{
Francisca Inês de Sousa Freitas ${ }^{1}$, Antonio Meza-Lucas², \\ Carlos Barbosa Lima ${ }^{3}$, Walfredo da Costa ${ }^{4}$, Ailton Melo ${ }^{5}$
}

\begin{abstract}
RESUMO - Este estudo contou com uma amostra de 110 pacientes epilépticos residentes no Cariri paraibano, tendo sido desenvolvido em três etapas sucessivas. Durante a primeira etapa, aplicou-se a ficha epidemiológica visando identificar fatores de risco associados ao complexo teníase-cisticercose na etiologia da epilepsia dos pacientes. A segunda etapa consistiu em exames imunológicos dos 110 pacientes com a utilização da técnica EITB para a identificação de anticorpos séricos anti-cisticercos, e da técnica ELISA para a presença de antígenos circulantes. Na terceira etapa, treze pacientes com sorologia considerada positiva foram submetidos a exames tomográficos. A partir da aplicação do questionário, foram detectados alguns fatores de risco. A soroprevalência constatada foi 118,2/1000 habitantes. Dos 13 pacientes com sorologia positiva para cisticercose, $46,1 \%$ têm lesões sugestivas de cisticercose de localização parenquimatosa. Conclui-se que os municípios estudados apresentam perfil epidemiológico compatível com a ocorrência do complexo teníase-cisticercose e que a cisticercose possivelmente desempenhe papel importante no surgimento da epilepsia nesses pacientes.
\end{abstract}

PALAVRAS-CHAVE: cisticercose, epilepsia, soroprevalência, complexo teníase-cisticercose.

\section{Cysticercosis research in epileptic patients dwelling in towns of the western Cariri in the State of Paraíba, Brazil}

\begin{abstract}
This research involved a sample of 110 epileptic patients from western Cariri, Paraíba, Brazil and it has been developed in three successive phases. During the first one, an epidemiological form was applied with the aim of identifying risk factors related to the taeniasis cysticercosis complex in the etiology of the patients' epilepsy. The second phase consisted of immunological exams of 110 patients, by means of the EITB technique to identify the anti-cysticerci serum antibodies, whereas the presence of circulating antigens was verified through the ELISA technique. In the third phase, thirteen patients who were seropositive, were submitted to brain CT scan. Applying the questionnaire enabled us to know some risk factors. The seroprevalence detected was $118.2 / 1000$ inhabitants. Out of the 13 seropositive patients for cystice rcosis, $46.1 \%$ presented parenchymal cysticercotical damage. Based on these results, we are able to conclude that the studed towns reveal an epidemiological profile which is compatible with the occurrence of the taeniasis cysticercosis complex and cysticercosis plays an important role in the sprouting of epilepsy in these patients.
\end{abstract}

KEY WORDS: cysticercosis, epilepsy, seroprevalence, taeniasis cysticercosis complex.

No Brasil, existem diversos tipos de endemias parasitárias cuja origem remonta à carência de saneamento básico e de educação sanitária, porém nenhuma delas parece tão fácil de ser erradicada quanto a cisticercose. Isto porque se trata de uma antropozoonose em que o suíno aparece tão-somente como uma vítima dos maus hábitos de higiene do ser humano. Assim sendo, o esgotamento do parasita no homem levaria à interrupção da cadeia de transmissão, tornando possível à erradicação da referida helmintose ${ }^{1,2}$. Tal fato torna ainda mais absurda a existência de uma tal parasitose. Ademais, convém lembrar que a maior parte dos indivíduos acometidos pertence aos extratos menos favorecidos da população. A cisticercose é definida como o acometimento dos tecidos dos hospedeiros intermediários (suínos) e dos anômalos (homens) pela forma larvária da Taenia solium (cisticerco) ${ }^{3}$; O cisticerco tem predileção pelos tecidos cerebrais nos quais se fixa produzindo uma das infecções mais graves do sistema nervoso central, a cisticercose cerebral ou neurocisticercose, cujas manifesta-

${ }^{1}$ Professora Adjunta no Departamento de Ciências Farmacêuticas da Universidade Federal da Paraíba, João Pessoa PB, Brasil (UFPB); ${ }^{2}$ Pesquisador do Instituto de Diagnóstico y Referencia Epidemiológicos do México, México DF; ${ }^{3}$ Professor Adjunto no Departamento de Enfermagem da UFPB; ${ }^{4}$ P rofessor Adjunto no Departamento de Infectologia da UFPB; ${ }^{5} \mathrm{P}$ rofessor no Programa de Pós-Graduação em Neurociências da Universidade Federal da Bahia, Salvador BA, Brasil.

Recebido 24 Setembro 2004, recebido na forma final 11 Janeiro 2005. Aceito 23 Março 2005. 
ções mais comuns são as crises epilépticas ${ }^{4,5}$. Tais crises resultam de agressões ao córtex cerebral e se caracterizam por desencadear desde simples perda de atenção até convulsões severas ${ }^{6}$. Segundo Román et al. ${ }^{7}$ e Boppré et al. ${ }^{8}$, a neurocisticercose é a principal causa de epilepsia nos países em desenvolvimento, incluindo o Brasil. Nos países desenvolvidos, ocorre preferencialmente nas áreas de maior concentração de imigrantes ${ }^{9,10}$. Portanto, neurocisticercose e epilepsia têm apresentação universal, embora estejam intimamente relaciona das à falta de estrutura social, econômica e cultural das populações atingidas e às condições básicas de saúde e sanitarismo dos países onde as prevalências encontram-se mais elevadas ${ }^{11}$.

Todavia, constata-se que poucos trabalhos foram realizados em nosso país ressaltando a importância da cisticercose na etiologia da epilepsia. Esta escassez torna-se mais grave quando constatamos que tais estudos possuem apenas caráter regional, inviabilizando, com isso, o conhecimento, em âmbito nacional, do grau de endemicidade da cisticercose e, sobretudo, da neuro cis ticercose enquanto causa de crises epilépticas ${ }^{1,12}$. A respeito da região Nordeste, os dados são ainda mais escassos. Este fato pode ser explicado pela falta de notificação, pela existência de diagnósticos imprecisos ou simplesmente porque diagnósticos e tratamentos são realizados, sobretudo, nos grandes centros do sul e sudeste do país. Em um estudo soroepidemiológico realizado em Brasília - DF, Viana et al. ${ }^{13}$ observaram maior proporção de sorologia positiva para cisticercose em indivíduos naturais dos Estados do Rio Grande do Norte, Piauí e Pernambuco, sendo que, naqueles provenientes da Paraíba, a porcentagem foi uma das mais baixas. Nos últimos anos, com a chegada de tomógrafos nos Estados nordestinos, os casos de neuro cisticercose começaram a ser diagnosticados. Em 1994, Albuquerque e GaIhardo ${ }^{14}$ diagnosticaram 8 casos de neurocisticercose no Rio Grande do Norte. Enquanto isso, em Campina Grande - PB, detectou-se 1,02\% de casos de cisticercose cerebral ${ }^{15}$.

Em face dessa situação, considera-se importante estudar a cisticercose em pacientes portadores de epilepsia, especialmente nas comunidades onde coexistem precárias condições sanitárias, presença de porcos criados livres próximos a áreas residenciais e um deficiente ou inexistente controle sanitário da carne suína, fatores estes que propiciam a manutenção do ciclo da Taenia solium e, conseqüentemente, a disseminação da cisticercose. Com isso, a ausência de um levantamento adequado, aliada à insuficiência de dados sobre a prevalência dessa enteroparasitose, nos levou a investigar sua prevalência em três municípios do Cariri paraibano, região suspeita de abrigar casos de neurocisticercose entre sua população.

\section{MÉTODO}

O universo de estudo foi constituído por 110 pacientes epilépticos em tratamento nos centros de saúde de três municípios do Nordeste do Brasil. Nos três municípios existiam 609 pacientes portadores de epilepsia cadastrados nos centros de saúde até 2001, distribuídos da seguinte forma: 39 pacientes em Prata, 69 em Camalaú e 501 em Monteiro. Em Prata, todos os pacientes concordaram em participar da pesquisa, em Camalaú somente 26 participaram e, em Monteiro, 45.

O estudo foi desenvolvido em três etapas sucessivas. Durante a primeira etapa, aplicamos a ficha epidemiológica elaborada pela Fundação Nacional de Saúde com a finalidade de identificar fatores de risco associados ao complexo teníase-cisticercose na etiologia da epilepsia dos pacientes. A segunda etapa constou de exames sorológicos com a finalidade de pesquisar anticorpos (Ac) anticisticerco e antígenos (Ag) de cisticercos de Taenia solium.

Para a identificação de Ac anti-cisticerco de $T$. solium foi utilizada a técnica conhecida como EITB (Enzime-lin ked Immunoelectrotransfer Blot Assay) como descrita por Tsang et al. ${ }^{16}$.

A identificação de Ag de cisticerco foi realizada mediante a técnica ELISA (Enzime-linked Immunosorbent Assay) devido à sua reconhecida eficácia como método de diagnóstico da cisticercose ${ }^{17}$.

$\mathrm{Na}$ terceira etapa, foram realizados exames de neuroimagem, cuja técnica utilizada foi a tomografia computadorizada do cére bro. Com o objetivo de diagnosticar cisticercos de localização cerebral, foram submetidos a exames tomográficos somente os 13 pacientes com sorologia considerada positiva por, pelo menos, uma das técnicas imunológicas utilizadas em nosso estudo. Este estudo foi aprovado pelo Comitê de Ética em Pesquisa do Centro de Ciências da Saúde da UFPB.

As informações coletadas nos questionários do presente estudo foram inseridas em um banco de dados e analisadas pelo pacote estatístico SPSS (Statistical Packa ge for the Social Sciences) versão for Windows (Release 8.0 - Standard Version). As variáveis qualitativas foram analisadas pelos testes do Qui-quadrado ou teste exato de Fischer.

\section{RESULTADOS}

Do contingente de 110 pacientes epilépticos, $65(59,1 \%)$ deles pertencem ao sexo feminino, enquanto $45(40,9 \%)$ são do sexo masculino. Dentre as faixas etárias mais afetadas, pode-se destacar principalmente a dos indivíduos acima de 20 anos, perfazendo o total de $56,4 \%$ da amostra. 
Por ocasião da aplicação do questionário, um número considerável de pacientes, 21 (19,3\%), afirmou que existiam casos de teníase entre seus familiares, enquanto $88(80,7 \%)$ atestaram a inexistência de casos e apenas 1 não soube responder a questão.

Com relação às condições de saneamento básico, constata-se que somente $5(4,5 \%)$ dos pacientes fazem uso de água encanada e tratada, ao passo que 105 (95,5\%) consomem água de outras fontes, $20(18,3 \%)$ contam com esgoto público, enquanto $89(81,7 \%)$ não possuem esgotamento sanitário. A respeito do local usado para evacuar, constatase que $59(53,6 \%)$ têm sanitário, $27(24,5 \%)$ evacuam em casinha de fundo de quintal e 24 (21,9\%) dos analisados ainda defecam a céu aberto.

Acerca da criação de porcos, observou-se que $9(8,2 \%)$ dos pacientes os criam e que $101(91,8 \%)$ não o fazem. Percebeu-se que o número de pacientes que consomem carne de suínos é baixo, pois apenas $24(21,8 \%)$ se alimentam do animal, enquanto $86(78,2 \%)$ ingerem outros tipos de carne. Um elevado número de pesquisados tem o hábito de comer verdura, $90(81,8 \%)$, sendo que deste, $28(31,1 \%)$ o fazem sem cozimento e $62(68,9 \%)$ com cozimento.

Dentre os 110 pacientes epilépticos submetidos a exames sorológicos, $9(81,8 / 1000)$ apresentaram Ac contra uma fração específica de Ag pela técnica de EITB e em $4(36,4 / 1000)$ de antígenos do parasita foram detectados através do teste ELISA. Somados os casos positivos mediante a pesquisa de Ac, com os obtidos pela pesquisa de Ag, chegouse a um total de 118,2/1000 de sorologia positiva para cisticercose.

O b s e rvou-se ainda que a faixa etária mais acometida situa-se acima de 49 anos, com soroprevalência de $363,6 / 1000$, seguida pelas faixas compreendidas entre 40 e 49 anos com 120,7/1000 e, por fim, pela de 5 a 19 anos com 48,8/1000 ( $p=0016<$ $0,05)$. Com efeito, acerca dos Municípios, constatou-se maior soro p revalência no Município de $\mathrm{Ca}$ malaú com 230,8/1000, seguido por Monteiro com $111,0 / 1000$ e, finalmente, Prata com 51,3/1000, mas estas diferenças não foram estatisticamente significativas $(p=0,88)$.

Dos 13 pacientes com sorologia positiva para cisticercose, $46,1 \%$ têm lesões sugestivas de cisticercose, enquanto $53,9 \%$ não apresentaram lesões compatíveis com a referida parasitose. Observouse ainda que todas as lesões eram de localização p a renquimatosa, sendo que apenas um paciente a $p$ resentou simultaneamente lesões parenquimatosas e subaracnóides. Acerca do estágio evolutivo do cisticerco, comprovou-se que em cinco pacientes o mesmo estava calcificado.

Constatou-se ainda que no Município de Camalaú concentra-se o maior percentual de pacientes com lesões sugestivas de cisticercose, $66,7 \%$, seguido por Monteiro, com 33,3\%. Ademais, no Município de Prata não ocorreu diagnóstico por neuroimagem.

\section{DISCUSSÃO}

$\mathrm{Na}$ amostra analisada, a prevalência da epilepsia variou de 11,4 a 18/1000 habitantes, sendo, portanto, superior às descritas nos países desenvolvidos, onde tem sido observada uma variação de 5 a 9/1000 habitantes. Da mesma forma, constatou-se que a doença acometeu pre $\mathrm{fe}$ rencialmente o sexo feminino (59,1\%). Este resultado contrapõe-se ao de Gomes et al. ${ }^{18}$, que atesta a existência de um p redomínio da epilepsia no sexo masculino ${ }^{18}$. Com efeito, percebe-se que ela atinge a maior parte dos indivíduos na faixa etária acima de 20 anos (56,4\%), caracterizando, assim, um predomínio da epilepsia de "início tardio", isto se adotarmos o $\mathrm{m}$ a rco de 18 anos preconizado por Rigatti e Tre visol-Bittencourt ${ }^{19}$. Esses autores identificaram, em estudos realizados numa Clínica de Epilepsia no Estado de Santa Catarina, a cisticercose como causa mais freqüente da epilepsia tardia.

A respeito das variáveis consideradas como fatores de risco para a manutenção do complexo teníase-cisticercose, foi possível deduzir que os pacientes investigados nesta pesquisa estão inseridos em um contexto que favorece não somente a manutenção, como também a propagação da referida parasitose. Esta inferência é compatível com os dados concernentes aos estudos epidemiológicos de Silva-Vergara et al..$^{20}$ e Viana et al. ${ }^{13}$. Nessa mesma perspectiva, considera-se alto o percentual $(19,3 \%)$ de participantes que afirmaram ter ocorr ido casos de teníase na família. Ora, sabe-se que o portador de tênia adulta constitui-se como uma fonte extremamente potente de infecção, tanto para si como para os seus contactantes e para os suínos, uma vez que elimina diariamente proglotes repletas de ovos ${ }^{21}$. Constata-se ainda que 8,2\% dos pacientes criam porcos. Estes fatos, quando associados às condições de saneamento básico desfavoráveis (somente $4,5 \%$ contam com água encanada, $18,3 \%$ possuem esgotamento sanitário em suas residências e $21,9 \%$ defecam a céu aberto), indicam a existência de fatores suficientes para a ocorrência do ciclo parasitário tênia/cisticerco. 
Quanto aos hábitos alimentares, acredita-se que algumas respostas oferecidas pelos sujeitos investigados não foram sinceras no que diz respeito ao consumo de carne suína, pois foi constatado que esses pacientes tinham vergonha de dizer que consumiam tal alimento pelo fato de associare $m$ a ingestão desse tipo de carne ao desenvolvimento da neurocisticercose, por eles denominada de "bicho do porco na cabeça". Eles informaram ainda que recebiam orientações médicas para não consumir carne suína sob pena de contrair o "bicho do porco". Sabe-se que essa orientação é no mínimo equivocada, na medida em que proibir a ingestão de carne suína, além de contribuir para o não reconhecimento público do homem como o principal mantenedor da parasitose em questão, priva pessoas carentes de utilizar um alimento com alto teor protéico e de fácil aquisição na região estudada. Mais uma vez se constata a vã tentativa de se atacar os efeitos do problema, deixando suas causas incólumes. A respeito da ingestão de verduras, foi possível verificar que $81,8 \%$ dos indivíduos responderam afirmativamente. Além disso, acerca de tal consumo, constata-se que as preparações cozidas foram as mais citadas (68,9\%), o que reduz o risco de os indivíduos infectarem-se com ovos de T. solium ocasionalmente presentes em verduras cruas.

Acerca dos aspectos relacionados aos exames so rológicos, constata-se, quando somados os resultados da pesquisa de anticorpos $(81,8 / 1000)$ com os da pesquisa de antígenos (36,4/1000), uma alta prevalência $(118,2 / 1000)$ de sorologia positiva para cisticercose. Estes dados são condizentes com os descritos por outros autores que, ao utilizarem técnicas semelhantes, observaram que, em vários países da América Latina (incluindo o Brasil) e da África, têm sido encontradas soroprevalências em portadores de epilepsia variando de 70 a 350/1000 habitantes ${ }^{18,22-25}$. No entanto, em uma pesquisa realizada em Brasília-DF, descobriu-se a existência de somente $0,6 \%$ de sorologia positiva para cisticercose em pacientes com epilepsia, tendo sido utilizados os testes imunoenzimáticos ELISA e imunofluorescência indireta ${ }^{13}$. Todavia, em estudos executados no Estado de São Paulo, demonstrouse que, dentre os pacientes internados em hospitais para port a doresde doenças mentais, 3,8\% apresentaram soropositividade para cisticercose $\mathrm{e}^{26}$. Posteriomente, Vaz et al. ${ }^{27}$ observaram uma freqüência de $5 \%$ de positividade nos pacientes investigados. Convém destacar que, no primeiro estudo, a técnica utilizada foi a reação de fixação do comple- mento, enquanto no segundo caso utilizou-se o ELISA.

Por outro lado, ao se avaliar a soroprevalência e a faixa etária dos indivíduos por nós investigados, é possível constatar a existência de uma relação de correspondência entre ambas, cujo nível mais alto alcançado ultrapassou os 49 anos $(p=0,016)$. Esses resultados sugerem que a cisticercose desempenha papel importante no surgimento da epilepsia tardia e que o risco de contaminação é tanto maior quanto mais prolongada for a exposição do ser humano ao parasito. Assim, somente é possível encontrar na literatura parâmetros de comparação com uma pesquisa realizada na África, na qual Dumas et al. observaram um aumento prog ressivo da cisticercose em epilépticos com a idade, sendo as taxas mais altas acima de 50 anos $^{28}$.

No nosso estudo, os exames tomográficos revelaram um alto percentual, dentre os soropositivos $6 / 13(46,1 \%)$, de pacientes com lesões sugestivas de cisticercose. Observou-se ainda que todas as lesões eram de localização parenquimatosa (somente um paciente apresentou simultaneamente lesões pa renquimatosas e subaracnóides) e que cinco deles $(83,3 \%)$ eram portadores de cisticercos calcificados e apenas um paciente apresentou o cisticerco em sua fase vesicular, mas já se encontrava envolto por um reforço anelar. Ao se considerar que calcificações intraparenquimatosas encefálicas são os achados tomográficos mais comumente presentes em pacientes com epilepsia decorrente da neurocisticercose ${ }^{29-32}$, pode-se inferir que a causa da epilepsia nos nossos investigados foi determinada pela referida parasitose. Com efeito, quando os critérios propostos por Del Brutto et al. ${ }^{33}$ são adotados, pode-se chegar a um diagnóstico definitivo da neurocisticercose, pois é possível reunir dois critérios, o Maior (soropositividade + lesões cisticercóticas), o Menor (a epilepsia como uma manifestação clínica sugestiva de neurocisticercose) e, finalmente, alguns critérios epidemiológicos (como no caso dos fatores de risco). No Brasil, estudos realizados com o objetivo de estabelecer a etiologia das crises epilépticas identificaram a neurocisticercose como uma de suas causas mais comuns, tendo ela sido constatada em $27,1 \%$ dos pacientes examinados por Arruda $^{34}$ e em 8,8\% daqueles investigados por Valença e Valença ${ }^{35}$.

Ao avaliar a distribuição da freqüência de pacientes com lesões cisticercóticas por município, evidencia-se que existe uma relação de correspondência entre os dados obtidos mediante exames 
so rológicos com aqueles decorrentes dos exames de neuroimagem, uma vez que no município de Camalaú, onde se detectou a mais alta soro prevalência, foi obtido também o maior percentual de pacientes com lesões cerebrais $(66,7 \%)$, seguido por Monteiro, município que apresenta a segunda maior sorop revalência e freqüência de lesões cerebrais $(33,3 \%)$ e, finalmente, Prata que apresentou a menor sorop revalência $(51,3 / 1000)$ e onde nenhum dos seus participantes estava acometido por lesões cerebrais sugestivas de cisticercose. Antes de se atingir tais resultados, tinha-se a expectativa de encontrar uma distribuição mais homogênea, uma vez que os pacientes habitantes dos três municípios vivem em um contexto sócio-econômico-cultural semelhante. Não se sabe, contudo, explicar os dados acima referidos, mas acredita-se que investigações futuras, mediante a utilização de uma amostra com maior amplitude, poderão fornecer respostas mais satisfatórias.

Todavia, este estudo se afigura como um passo importante para a identificação da prevalência da cisticercose no Estado da Paraíba, podendo ainda fo rnecer subsídios ou diretrizes para a elaboração de políticas públicas de saúde destinadas à prevenção, combate e erradicação do complexo teníase-cisticercose em nosso meio. Na casuística do presente estudo existe um predomínio de epilepsia de início tardio $(56,4 \%)$, fazendo supor que a cisticercose desempenha um papel importante no surgimento da epilepsia nos pacientes dos municípios em estudo. Os pacientes analisados apresentam uma elevada soroprevalência para cisticercose $(118,2 / 1000$ habitantes), semelhante àquelas dos países endêmicos da América Latina e África. Em $46 \%$ dos pacientes soropositivos, diagnosticou-se casos de neurocisticercose cujas lesões eram calcificadas e de localização parenquimatosa. Considerando-se que as manifestações clínicas predominantes de cisticercose parenquimatosa são as crises epilépticas, sugere-se que a referida parasitose é a causa da epilepsia nos pacientes analisados.

\section{REFERÊNCIAS}

1. Fundação Nacional de Saúde. CCZAP. Projeto para o controle do complexo teníase/ cisticercose no Brasil, Brasília, DF, 1996.

2. Sarti EMC. La teniasis y cisticercosis por Taenia solium. Salud Púb Méx 1997; 39:225-230.

3. Simas ZMG; Kameoka RFA. Neurocisticerose. J Bras Med 1992; 63: 15-37.

4. Flisser A. Neurocysticercosis and epilepsy in developing countries. J Neurol Neurosurg Psychiatry 2001; 70:707-708.

5. Ga raia-Noval J, Moreno E, Mata F, et al. An epidemiological study of epilepsy and epileptic seizures in two rural Guatemalan communities. Ann Trop Med Parasitol 2001; 95:167-175.
6. L'Épilepsie: étiologie, épidemiologie et pronostic. Disponível em: $<$ http/ / www.who.int/inf-fs/am165.html>. Acesso em: 14 nov. 2001. (Aide-mémoire, n. 165).

7. Rómán G, Sotelo J, Del Brutto O. et al. A proposal to declare neurocysticerosis an international reportable disease. Bull World Health Organ 2000;78:399-406.

8. Boppré MCP, Wille PR, Guarnieri R. et al. Cognitive performance of patients with epilepsy and calcified neurocysticercotic lesions: a casecontrol study. Epilep Behav 2001;2:558-562.

9. White AC Jr. Neurocysticercosis: updates on epidemiology, pathogenesis, diagnosis, and managament. Ann Rev Méd 2000;51:187-206.

10. Duchêne M, Benoudiba F, Iffenecker C, Hadj-Rabiam, Caldas JGMP, Doyon D. La neurocisticercose. J Radiol 1999;80:1623-1627.

11. Pal DK, Sander JWAS. Neurocysticercosis and epillepsy developing countries. J Neurol Neurosurg Psychiatry 2000;68:137-143.

12. Takayanagui OM, Castro e Silva AAMC, Santiago RC, Odashima NS, Terra VC, Takayanagui AMM. Notificação compulsória da cisticercose em Ribeirão Preto-SP. Arq Neuropsiquiatr 1996; 54:557-564.

13. Viana LG, Macedo V, Costa JM, Mello P, Souza D. Estudo soroepidemiológico da cisticercose humana em Brasília, Distrito Federal. Rev Soc Bras Med Trop 1986;19:149:153.

14. Albuquerque ES, Galhardo I. Neurocisticercose no Estado do Rio Grande do Norte: relato de oito casos. Arq Neuropsiquiatr 1995;53:464-470.

15. Gonçalves-Coêlho TD, Coêlho MG. Cerebral cysticercosis in Campina Grande - Paraíba - Northern Brazil. Arq Neuropsiquiatr 1996;54:94-97.

16. Tsang VCW, Brand JA, Boyer AE. An enzyme-linked immunoeletrotransfer blot assay and glycoprotein antigens for diagnosing. J Infec Dis 1989;159:50-59.

17. Aranda-Alvarez JG, Tapia-RomeroR, Alcântara-Anguiano Y, et al. Human cysticercosis: risk factors associated with circulating serum antigens in an open community of San Luis Potosí, Mexico. Ann Trop Med Parasitol 1995;89:689-692.

18. Gomes I, Veiga M, Correa D, et al. Cisticercosis in epileptic patients of Mulungu do Morro Northeastern Brazil. Arq Neuropsiquiatr 2000;58:1-9.

19. Rigati M, Trevisol-Bittencourt PC. Causas da epilepsia tardia em uma clínica de epilepsia do Estado de Santa Catarina. A rq Neuropisquitr 1999;57:787-792.

20. Silva-Ve rgara ML, Aluízio P, Vieira CO, et al. Aspectos epidemiológicos da teníase-cisticercose na área endêmica de Lagamar, MG. Rev Soc Bras Med Trop 1995;28:345-349.

21. Takayanagui O M, Leite JP. Neurocisticercose. Rev Soc Bras Med Trop 2001;34:36-48.

22. Correa D, Sarti E, Tapia-RomeroR et al. Antigens and antibodies in sera from human cases of epilepsy or taeniasis from an area of Mexico where Taenia solium cysticercosis is endemic. Ann Trop Méd Parasitol 1999;93:69-74.

23. Gacia-Garcia ML, Torres M, Correa D. et al. Prevalence and risk of cisticercosis and taeniasis in an urban population of soldiers and their relatives. Americ Soc Trop Med Hyg 1999;61:386-389.

24. Sánchez AL, Lindbäck J, Schantz PM, et al. A population-based, casecontrol study of Taenia solium taeniasis and cisticercosis. Ann Trop Med Parasitol 1999;93:247-258.

25. Balogou AAK, Grunitzky KE, Beketika, Bouteille B, Dumas M. Cisticercose et épilepsie au nord du Togo dans le Tone. Rev Neurol (Paris) 2000;156:270-273.

26. Ueda M, Nakamura PM, Waldman EA, et al. Freqüência de Ac anticysticercus cellulosae em população de risco para cisticercose e em segmento de população considerado supostamente normal em regiões do Estado de São Paulo, Brasil. Rev Inst Adolfo Lutz 1984; 44:25-28.

27. Vaz AJ, Hanashiro ASG, Chieffi PP, Ferreira AW. Freqüência de indivíduos com anticorpos séricos anti-cysticercus cellulosae em cinco municípios do Estado de São Paulo. Rev Soc Bras Med Trop 1990;23:97-99.

28. Dumas M, Grunitzky K, Belo M, et al. Cysticercose et neurocisticercose: enquête épidémiologique dans le nord du Togo. Bull Soc Path 1990; 83:263-272.

29. Narata AP, Arruda WO, Uemura E, et al. Diagnóstico tomográfico em pacientes neurológicos. Arq Neuropsiquiatr 1998; 56:245-249.

30. Hernández-Cossio O, Hernández-Fustes OJ. Neurocisticercosis y epilepsia en Cuba. Rev Neurol 1999;29:1003-1006.

31. Del Bruto OH. Neurocisticercosis. Rev Neurol 1999;25:456-466.

32. Singhi PD, Baranwal. Singel small enhancing computed tomographic lesions in indian children: II. Clinical features, patology, radiology and management. J Trop Pediat 2001;47:266-270.

33. Del Bruto OH. Proposal of diagnostic criteria for human cisticercosis and neurocysticercosis. J Neurol Sci 1996;142:1-6.

34. Arruda WO. Etiology of epilepsy: a prospective study of 210 cases. Arq Neuropsiquiatr 1991;49:251-254.

35. Valença MM, Valença LPAA. Etiologia das crises epilépticas na cidade do Recife, Brasil: estudo de 249 pacientes. A rq Neuropsiquiatr 2000;58: $1-14$. 